\title{
Inhibition of Schwann Cell Myelination in vitro by Antibody to the L1 Adhesion Molecule
}

\author{
Patrick M. Wood, ${ }^{1, a}$ Melitta Schachner, ${ }^{2}$ and Richard P. Bunge ${ }^{1, a}$ \\ 'Department of Anatomy and Neurobiology, Washington University School of Medicine, St. Louis, Missouri 63110 and \\ 2Department of Neurobiology, Swiss Federal Institute of Technology, Hönggerberg, 8093 Zürich, Switzerland
}

\begin{abstract}
The specific axonal and Schwann cell surface molecules that mediate the initiation of myelination have not been identified. We have used cocultures of purified rat dorsal root ganglion neurons and Schwann cells and purified polyclonal antibodies to the L1 adhesion molecule to study the role of L1 in myelin formation. Schwann cells were first arrested in a basal-lamina-free premyelination stage (by serum/ascorbate deprivation), then manipulated to allow basal lamina deposition and myelination (by serum/ascorbate addition) in the absence or presence of anti-L1. Using electron microscopy, immunocytochemistry, and myelin sheath quantitation after Sudan-black staining, we determined the effect of anti-L1 on (1) basal lamina formation, (2) the segregation by Schwann cells of axons into a 1:1 relationship, (3) galactocerebroside (Gal-C) expression, (4) laminin deposition, and (5) myelin formation. Anti-L1 strongly blocked myelin formation, Gal-C expression, and axon segregation but did not block basal lamina formation. In controls, elongated Schwann cell processes completely covered the axons and exhibited uniform surface staining for laminin; in anti-L1-treated cultures, shortened Schwann cells, intensely stained for laminin, were observed in clusters separated by unstained lengths of axons. When $50 \mu \mathrm{g} / \mathrm{ml}$ exogenous purified laminin was added to the medium, Schwann cell length and laminin staining were similar in control and treated cultures. However, the inhibition of myelination by anti-L1 was not altered by the addition of laminin. Myelination was also inhibited with antigen-binding fragments (Fab) of polyclonal anti-L1, but an antibody to liver membranes did not block myelination. These results indicate that $L 1$ is involved in the linear extension of Schwann cell processes along axons, the engulfment of axons, and the induction of myelin-specific components within the Schwann cell. We conclude that anti-L1 prevents myelination by blocking these events rather than by blocking basal lamina deposition.
\end{abstract}

\footnotetext{
Received Apr. 4, 1990; revised June 21, 1990; accepted June 28, 1990.

We wish especially to acknowledge the important contribution to this work by Mrs. Margaret Bates, who performed the electron microscopy. We would also like to thank Mrs. Artree James and Mrs. Laura Tynan for expert technical assistance and Ms. Charlaine Rowlette for her patient and cheerful cooperation in preparing the manuscript. Dr. Barbara Ranscht and Dr. Erkki Ruoslahti provided antibodies to $\mathrm{Gal}-\mathrm{C}$ and laminin, respectively. Photographic assistance was provided by the late Mr. Robert Kuhlenberg. This work was funded by National Multiple Sclerosis Society Grant RG-1118, National Institute of Neurological Disorders and Stroke Grant NS19923-07, and grants from BMFT and KWF to M.S.

Correspondence should be addressed to Patrick M. Wood, Ph.D., The Miami Project to Cure Paralysis, Iniversity of Miami, School of Medicine, 1600 N.W 10 th Avenue, R-48, Miami, FL 33136.

a Present address: The Miami Project, University of Miami, School of Medicine, 1600 N.W. 10th Avenue, R-48, Miami, FL 33136.

Copyright (C) 1990 Society for Neuroscience 0270-6474/90/113635-11\$03.00/0
}

The molecular interactions at the axon-Schwann cell interface that initiate the formation of myelin sheaths are likely to involve molecules not specific for, or abundant in, myelin membranes. Several nonmyelin cell-surface proteins have been identified on neurons and Schwann cells that could participate in these initial interactions. These include the $\mathrm{Ca}^{2+}$-dependent adhesion molecule $\mathrm{N}$-cadherin (reviewed in Bixby et al., 1988) and the $\mathrm{Ca}^{2+}$ independent adhesion molecules NCAM (Thiery et al., 1977; Martini and Schachner, 1986, 1988; Pollerberg et al., 1987) and L1 (Rathjen and Schachner, 1984; Seilheimer and Schachner, 1988; Seilheimer et al., 1988a,b). Both NCAM and Ll are present on the membranes of axons and Schwann cells before the onset of myelination, but are reduced or are not detectable on Schwann cells soon after myelination commences (i.e., after the myelinating Schwann cell completes 1 1/2 layers of compact myelin around the axon; Martini and Schachner, 1986, 1988). NCAM and L1 continue to be weakly expressed on nonmyelinating Schwann cells even in adult nerves (Faissner et al., 1984). There is evidence that the adhesion molecule L1 might be involved in the contact or adhesion relationship between neurons and Schwann cells (Seilheimer and Schachner, 1988), but, as will be discussed below, L1 cannot be the only molecule involved in maintaining this relationship. $\mathrm{L} 1$ has also been shown to be involved in the interaction that promotes the growth of neurites over Schwann cell surfaces (Bixby et al., 1988; Kleitman et al., 1988; Seilheimer and Schachner, 1988). Recently, L1 has been further implicated in developmental neuron-Schwann cell interactions (Seilheimer et al., 1989b). It was demonstrated that antibodies to L1 added to mouse neuron-Schwann cell cocultures 1-2 hr after the addition of the Schwann cells blocked the ability of the Schwann cells to contact and ensheathe axons, to form basal lamina, and to express myelin-associated glycoprotein (MAG). Curiously, Schwann cell proliferation was not affected by the antibody, implying that transient association with neurons might have occurred in these cultures in the presence of the antibody. Anti-NCAM antibodies, in contrast, had relatively minor effects on these neuron-Schwann cell developmental interactions. It must be emphasized that myelination was not observed in this type of culture preparation, for reasons that are not known.

We have used a different culture system (described in detail in Eldridge et al., 1987, 1989) in which extensive myelination does occur to study further the role of L1 in Schwann cell development, and specifically in myelination. Because the ability of the Schwann cell to form myelin sheaths is rigorously linked, by an unknown mechanism, to its ability to form basal lamina, the neuron-Schwann cell cocultures can be restrained from myelination by withholding serum and ascorbic acid, both of which are required for basal lamina formation, from the culture me- 
dium. This permits some of the earlier relationships between the Schwann cells and axons (such as recognition, adhesion, proliferation, and the induction of synthesis of early myelin components) that do not require serum and ascorbate to be established prior to antibody treatment (Eldridge et al., 1989). Therefore, after the addition of the Schwann cells to the neuronal cultures, the Schwann cells adhere tightly to the axons and proliferate to cover areas of the culture occupied by axons, but they cannot form basal lamina or myelin. Myelination is initiated by the addition of serum and ascorbic acid to the medium, and the antibody treatment is begun at the same time.

We report here that, under these conditions, anti-L1 did not interfere with the ability of the Schwann cells to maintain their contact to axons or to form basal lamina, both of which would be prerequisites for myelination. However, anti-L1 strongly blocked myelination, suggesting an involvement of the Ll adhesion molecule in an event that occurs later in the sequence leading to myelination than those blocked in earlier experiments (Seilheimer et al., 1989).

\section{Materials and Methods}

Purification of cells. The methods for preparing culturcs of both Schwann cells and dorsal root ganglion (DRG) cultures and the addition of purified Schwann cells to these neuronal cultures have been described in detail elsewhere (Bunge et al., 1983; Eldridge et al., 1987). Briefly, DRGs were obtained from fetal rats on the 15 th $\mathrm{d}$ of gestation, dissociated, and cultured with periodic use of the antimitotic agent fluorodeoxyuridine (FdU) to remove non-neuronal cells. These cultures were reseeded with purified Schwann cells prepared separately. The Schwann cells used for reseeding were obtained from cultures of DRG explants that had been subjected to a course of treatment with FdU that resulted in many Schwann cells and essentially all fibroblasts being killed (Bunge et al., 1983). In these explant cultures, a remnant population of Schwann cells remained after the antimitotic treatment; this population was induced to expand in response to new axons growing from the DRG explants after transplantation. Pure Schwann cells wcrc obtaincd from these cultures following removal of the DRG explant. After reseeding with these purified Schwann cells, the dissociated neuron-Schwann cell cultures were maintained in a serum- and ascorbate-free medium, prepared by mixing Dulbecco's Modified Eagle's medium and Ham's F-12 medium (1:1) and adding rat transferrin $(10 \mu \mathrm{g} / \mathrm{ml})$, bovine insulin $(5 \mu \mathrm{g} / \mathrm{ml})$, sodium selenite (to $30 \mathrm{nM}$ ), progesterone (to $20 \mathrm{~nm}$ ), putrescine dihydrochloride (to $100 \mu \mathrm{M}$ ), and purified (2.5S) NGF $(100 \mathrm{ng} / \mathrm{ml})$. This medium was designated SA - medium. During the following 2-3 weeks, the added Schwann cells proliferated to cover the neuritic network at moderate density. At this point, they were ready for use in blocking experiments.

Medium shift to induce Schwann cell differentiation and treatment of cultures with $L 1$ antibodies. Schwann cell differentiation was initiated by replacing SA - medium with Eagle's minimum essential medium containing $15 \%$ heat-inactivated human placental or fetal bovine serum, $50 \mu \mathrm{g} / \mathrm{ml}$ ascorbate, glucose (350 mg\%), and partially purified NGF (at an empirically determined optimal concentration). This medium was designated SA + medium. Myelin formation was observed in these cultures within 1 week after the medium shift. For blocking experiments, anti-Ll antibody was added to the $\mathrm{SA}+$ medium at a concentration predetermined to saturate binding sites. Saturation was determined by visually evaluating the intensity of immunostaining observed with various dilutions of the antibody (using cultures similar to those used in the experiment). This test was repeated for each new antibody preparation. Concentrations ranging from 20 to $100 \mu \mathrm{g} / \mathrm{ml}$ (and, in 1 experiment, up to $400 \mu \mathrm{g} / \mathrm{ml}$ ) of intact $\mathrm{L} 1$ antibody (SA+/anti-L1 medium) or $200-250 \mu \mathrm{g} / \mathrm{ml}$ of Fab fragments of the Ll antibody (SA+/anti-L1 Fab medium) were uscd, depending on the activity of the antibody preparation. The binding and blocking activity of the antibody preparations used was a function of the method of preparation; immunoaffinity-purified antibodies were most active. In 1 experiment, some cultures were treated with polyclonal antibodies to a mouse-liver-membrane preparation that reacts with the surface of Schwann cells and neurons. All antibodies were added at the time the cultures were shifted from
$\mathrm{SA}-$ to $\mathrm{SA}+$ medium. Because our observations showed that the removal of the bound $\mathrm{L} 1$ antibody from the axonal surface by endocytosis was relatively slow (see Results), and because the antibody activity did not appear to decrease in medium stored at incubator temperature for $48 \mathrm{hr}$, the medium was replaced every $48 \mathrm{hr}$ (rather than every $24 \mathrm{hr}$ ) during the course of the blocking experiment. Unfixed cultures were immunostained and fixed for analysis at 8-12 $\mathrm{d}$ following the shift from $\mathrm{SA}-$ to SA + medium, when substantial myelination was observed in control cultures.

Sudan-black staining and myelin quantitation. Myelin sheaths were visualized and quantitated in cultures by staining with Sudan black. The cultures were rinsed with L-15 (Leibovitz) medium and fixed overnight at $4^{\circ} \mathrm{C}$ in $4 \%$ paraformaldchydc in $0.1 \mathrm{~m}$ sodium phosphate buffer $(\mathrm{pH}, 7.4)$. They were rinsed with buffer, postfixed with $0.1 \%$ osmium tetroxide for $1 \mathrm{hr}$ at room temperature, dehydrated to $70 \%$ ethanol, stained for $1 \mathrm{hr}$ in $0.5 \%$ Sudan black in $70 \%$ ethanol, rehydrated, and mounted in glycerin jelly. In general, myelin was quantitated by counting segments over equal-sized areas in duplicate control and experimental cultures. In experiments in which control numbers of segments were low (fewer than 2000 segments/culture), equally spaced strips totaling $1 / 4-1 / 2$ the entire culture area were scanned in each culture. In experiments in which myelin formation was more extensive, 25-50 fields at $2-\mathrm{mm}$ intervals as determined by stage coordinates were counted using an eyepiece grid. The magnification used for counting was $640 \times$

Preparation of antibodies. The preparation of antibody to mouse L1 and its immunoaffinity purification has been described previously (Faissncr et al., 1984; Martini and Schachner, 1986). Fab fragments of anti-L1 were prepared according to Porter (1959). The preparation of antibodies to mouse-liver membrane has also been described (Lindner et al., 1983; Pollerberg et al., 1987). Monoclonal antibody (2 E8) to laminin was a generous gift from Dr. Erkki Ruoslahti (Engvall et al., 1986). Monoclonal anti-galactocerebroside was obtained as a supernatant from cultured hybridoma cells provided by Dr. Barbara Ranscht (Ranscht et al., 1982). All secondary antibodies were obtained from Organon Technika.

Immunostaining. Living cultures were rinsed 2-3 times with Leibovitz (L-15) medium supplemented with $10 \%$ heat-inactivated horse serum (L-HS medium), then incubated with primary antibody (either mouse monoclonal antibody to Gal-C as an undiluted hybridoma culture supernatant or mouse monoclonal antibody to laminin as ascites fluid diluted 1:20 in L-HS medium) for $30 \mathrm{~min}$ at room temperature. The cultures were rinsed 3 times with L-HS medium, then incubated with secondary antibody (rhodamine-conjugated goat anti-mouse immunoglobulin, diluted 1:100 in L-HS medium) for $30 \mathrm{~min}$ at room temperature. To detect bound $\mathrm{Ll}$ antibody in cultures maintained in the presence of $\mathrm{L} 1$ antibodies, cultures were rinsed and incubated with fluorescein-conjugated goat anti-rabbit immunoglobulin (diluted 1:100 in L-HS medium). After incubation with the antibodies, the cultures were rinsed with L-15 and fixed by immersion in $5 \%$ acetic acid in absolute ethanol at $-20^{\circ} \mathrm{C}$ for $10 \mathrm{~min}$. The cultures were rinsed twice in $0.1 \mathrm{M}$ sodium phosphate buffer and mounted in a phosphate-buffered glycerol mountant containing antibleachants (Citifluor LTD) and Hoechst 33342 dye (Sigma Chemical Co.), a fluorescent stain for cell nuclei.

Electron microscopy. Living cultures were rinsed with L-15 and fixed and processed for electron microscopy as described previously (Bunge et al., 1989). Areas of similar cell density in the plastic-embedded control and experimental cultures were chosen by phase-contrast microscopy, marked, and excised for sectioning. The areas chosen were always located in the axonal outgrowth region of the cultures, where Schwann cell differentiation was most uniform. A total of 7 areas in control and 7 areas in anti-L1-treated cultures were examined by electron microscopy. Electron micrographs were examined to determine the extent to which basal lamina had formed and the extent to which Schwann cells had established a 1:1 relationship with axons.

Laminin addition. Laminin addition is known to be effective in permitting myelin formation in cultures in which vitamin $C$. deprivation prevents basal lamina formation by the Schwann cell (Eldridge et al., 1989). In 1 blocking experiment, purified laminin was added to the culturc medium. This laminin was obtaincd from Collaborative Research, Inc. and used without further purification or characterization. This laminin was purified from basement membrane of EngelbrethHolm-Swarm (EHS) mouse tumor cells and was supplied as a frozen solution at $1 \mathrm{mg} / 0.6 \mathrm{ml}$ in $0.05 \mathrm{M}$ Tris- $\mathrm{HCl}$ in $0.15 \mathrm{M} \mathrm{NaCl}(\mathrm{pH}, 7.4)$. The solution was slowly thawed at $4^{\circ} \mathrm{C}$ and was diluted to $50 \mu \mathrm{g} / \mathrm{ml}$ in ice-cold culture medium. 


\section{Results}

Induction of Schwann cell differentiation by serum/ascorbate Within the first wcck following the shift from SA to SA+ medium, we observed the following in control cultures: (1) elongation of Schwann cells, (2) increased deposition of laminin on the Schwann cell surface, (3) formation of basal lamina, (4) segregation of large axons into a 1:1 relationship of Schwann cells, and (5) the onset of myelination. These changes in Schwann cell morphology and in cellular relationships were in agreement with those reported earlier (Eldridge et al., 1987, 1989) and are not illustrated here.

\section{L1 localization on neurons and Schwann cells}

The distribution of L1 on neuronal and Schwann cell surfaces in $\mathrm{SA}-$ and $\mathrm{SA}+$ medium is shown in Figure 1, $a-d$. After immunostaining, LI appeared to be evenly distributed along the axonal surface in both $\mathrm{SA}-$ and SA+ media (Fig. 1 $b, d$ ). The staining observed in SA+ medium was clearly less intense than that in SA - medium. This difference could reflect the more complete and tighter covering of axonal surfaces by Schwann cell processes in SA+ medium. Relatively much lower levels of L1 were observed on Schwann cell surfaces, which appear completely L1 negative in the photographs shown here. In cultures carried in SA + medium to the point of myelination, L1 staining was absent from myelinating Schwann cells and could not be detected on axons within myelin internodes. These results are in agreement with the reported downregulation of L1 on Schwann cells in culture with neurons (Seilheimer et al., 1989a) and on myelinating Schwann cells (Martini and Schachner, 1986, 1988). However, in areas of low Schwann cell density in neuronSchwann cell cultures, or in cultures of Schwann cells without neurons, a weak, punctate expression of L1 could be detected on the Schwann cell surface.

\section{Anti-L1 blocks myelin formation}

Myelin formation was strongly inhibited in a dose-dependent manner if purified polyclonal anti-L1 antibody was added to the $\mathrm{SA}+$ medium (SA+/anti-Ll medium) at the time the cultures were shifted from $\mathrm{SA}-$ to $\mathrm{SA}+$ medium (Fig. 1e, Table 1). In the experiment illustrated, inhibition was greater than $90 \%$ at $50 \mu \mathrm{g} / \mathrm{ml}$ of the antibody. In SA+/anti-L1 medium, the Schwann cells were not as elongated as those in SA+ medium, and the few myelin segments formed were shorter, on average, than those in SA+ medium. Cultures in SA+/anti-L1 medium resembled untreated cultures kept in SA- medium; that is, the Schwann cells appeared rounded, but remained strongly adherent to the axons (i.e., the Schwann cells did not detach and migrate away from the axons or float off in the culture medium). When myelin sheaths were found in anti-L1-treated cultures, they were usually in thick fascicles or areas of high cell density. This suggested that Schwann cells in these areas may have escaped inhibition because antibody failed to penetrate into these regions of the culture, as observed in other experiments (Mithen et al., 1983; Ranscht et al., 1987).

In cultures treated continuously for $8 \mathrm{~d}$ with intact antibody (IgG) and finally stained with a secondary antibody, the axons exhibited small, intensely stained patches of L1-L1-antibody complex separated by short lengths of L1-negative axon. The degree of inhibition of myelination at different antibody concentrations was proportional to the degree of patching observed at those concentrations (e.g., maximal patching and inhibition of myelination were observed at $50 \mu \mathrm{g} / \mathrm{ml}$ ). However, patching of the L1-anti-L1 complex was not essential for inhibition of myelination by anti-L1. In other experiments, myelination was inhibited by monovalent Fab fragments of polyclonal anti-L1 (Table 2). As visualized by staining with secondary antibody, the bound L1 Fab fragments were evenly distributed over the axons (Fig. $1 e, f$ ). In antibody-treated cultures, the intensity of staining was equivalent to that seen in freshly stained control cultures in SA - medium (Fig. $1 b$ ). In 1 experiment, the removal of the L1-L1-Fab complex was monitored in antibody-free medium following a 24-hr incubation in the presence of $\mathrm{Ll}$ Fab fragments. Decreased but clearly demonstrable levels of bound L1-Ll-Fab complex remained even after $96 \mathrm{hr}$ in antibody-free medium. Those results indicate that bound anti- $\mathrm{Ll}$ is retained on the axon surface for long periods.

\section{Anti-LI blocks Gal-C expression}

Although myelin does not form in neuron-Schwann cell cultures maintaincd on SA - medium, many Schwann cells display Gal-C on their surfaces (Fig. 2a,b). The number of Gal-C-positive (Gal$\mathrm{C}+$ ) Schwann cells in SA- medium is much higher than one would predict based on the percentage of axons expected to become myelinated and on the number of Schwann cells that actually form myelin sheaths when the cultures are placed in myelinating conditions (i.e., in $\mathrm{SA}+$ medium). In some areas of cultures maintained in SA - medium, nearly all the Schwann cells were Gal-C+. After the shift to SA + medium, the Schwann cells that formed myelin sheaths remained Gal-C+ (Fig. $2 c, d$ ); however, nearly all the Schwann cells that did not form myelin sheaths became Gal-C negative ( $\mathrm{Gal}-\mathrm{C}-$ ). Thus, somewhat paradoxically, the percentage of Schwann cells that were Gal-C+ decreased as a result of the shift from nonmyelinating to myelinating conditions. In cultures that were shifted to $\mathrm{SA}+/ \mathrm{anti}-\mathrm{Ll}$ medium $(50 \mu \mathrm{g} / \mathrm{ml})$, very few Gal-C+ Schwann cells were observed (Fig. $2 e, f$ ), in parallel with the inhibition of myelination (i.e., the number of Gal-C-expressing Schwann cells in anti-L1treated cultures was much lower than in control cultures). AntiL1 thus blocked the expression of Gal-C on those Schwann cells that would have formed myelin sheaths in the absence of antiL1.

\section{Anti-L1 blocks the segregation of large axons into a 1:1 relationship}

The effects of anti-L1 antibody on the structural relationship between axons and Schwann cells and on basal lamina formation were studied by electron microscopy. In control cultures, Schwann cells "engaged" axons by extending 2 or more processes into axon bundles; these processes often bifurcated to separate or to engulf several axons (Fig. $3 a$ ). We have used the term "engaged" here deliberately to denote the dynamic and transitory interaction between Schwann cell processes and axons that precedes the permanent "ensheathment" of axons that occurs as the Schwann cell-axon relationship matures. In anti-L1treated cultures, close contact between the axon and Schwann cells was maintained (cf. Fig. 3a,b); cultures treated with antiLl were morphologically similar to those in SA- medium (i.e., to cultures prior to shifting to myelinating conditions). The percentage of Schwann cells observed to be engaged with axons was similar in control and anti-Ll-treated cultures (Table 3). However, in treated cultures, engagement was less complete; the 

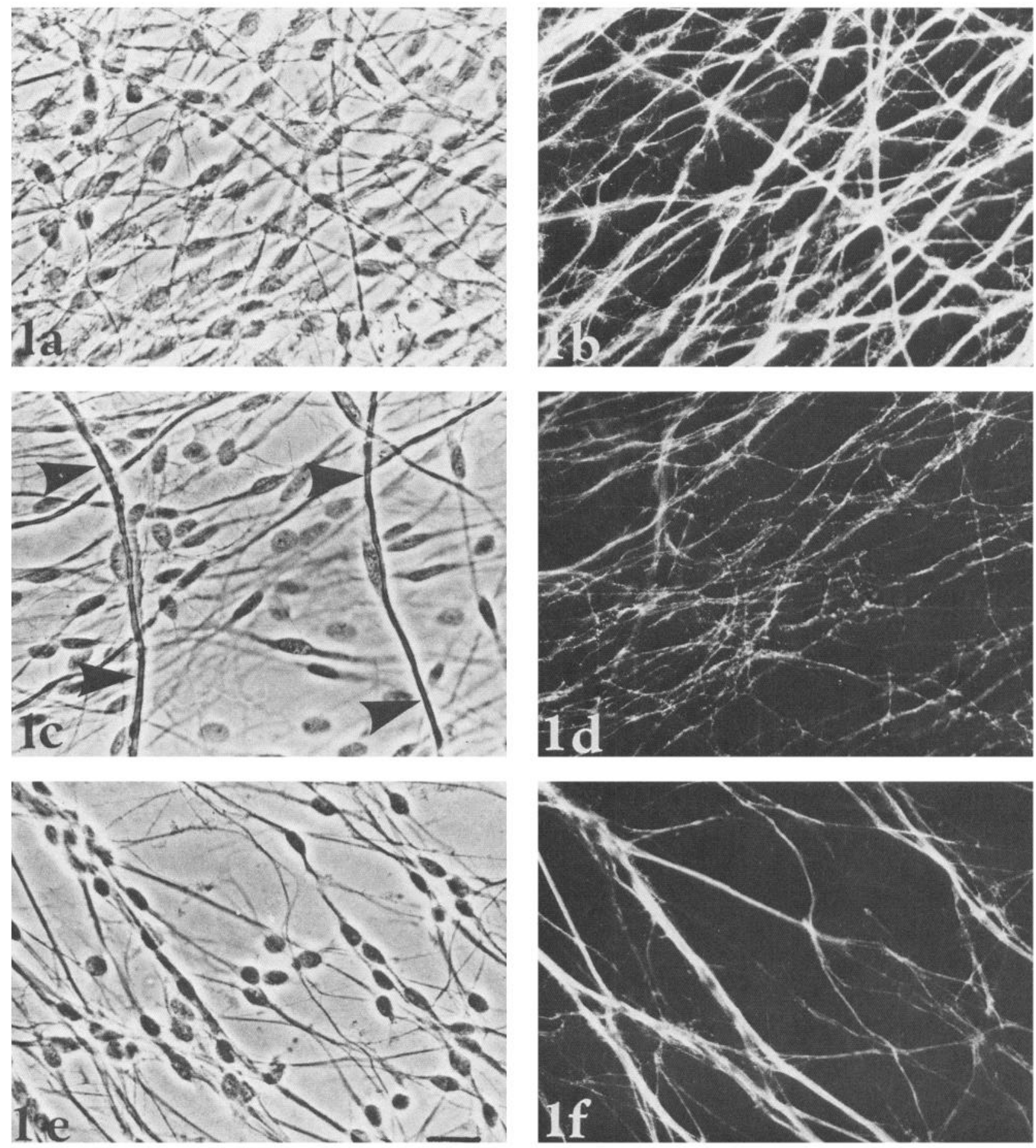

Figure 1. Binding of anti-L1 antibody to neuron-Schwann cell cultures in SA-, SA+, and SA+/anti-L1 Fab medium. Phase (a) and fluorescence (b) images of a culture maintained in SA - medium and immunostained with intact anti-L1 antibody and fluorosceinated goat anti-rabbit secondary antibody. These photographs illustrate the configuration of the Schwann cells and the distribution of L1 at the point of shifting to SA+ medium. Note the localization of L1 predominantly on axons. Phase-contrast $(c)$ and fluorescence $(d)$ images of a culture immunostained with intact L1 antibody 2 weeks after shifting to SA+ medium. Numerous myelin sheaths were visible, and the Schwann cells were longer than those in SAmedium. Myelinating Schwann cells and myelinated axons appeared completely L1 negative [e.g., the internodes visible in $c(a r r o w h e a d s)$ is invisible in $d$ ]. Phase-contrast $(e)$ and fluorescence $(f)$ images of a culture stained with secondary antibody only 2 weeks after shifting into SA $+/$ anti-L1 Fab medium. Schwann cells appeared rounded, and most of the axonal surface was exposed. The L1-anti-Ll complex appeared unpatched and was localized on the axons. Scale bar, $10 \mu \mathrm{m}$. 


\begin{tabular}{lll}
\hline $\begin{array}{l}\text { Table 1. } \\
\text { antibody }\end{array}$ & Dose-dependent inhibition of myelination by intact L1 \\
$\begin{array}{lll}\text { Anti-L1 } \\
(\mu \mathrm{g} / \mathrm{ml})\end{array}$ & Myelin segments per $\mathrm{mm}^{2}$ & Inhibition $(\%)$ \\
\hline 0 & $200(176,223)$ & \\
10 & $140(69,150,201)$ & 30 \\
20 & $85(63,97,97)$ & 58 \\
50 & $18(16,18,20)$ & 91
\end{tabular}

Myelin segments were counted on Sudan-black-stained whole-mounted cultures (see Materials and Methods). The results are the average of determinations on duplicate or triplicate cultures; individual values are shown in parentheses.

Schwann cells extended either a single long process or a few shorter ones (Fig. 3b), and the extent to which Schwann cell processes were observed between bundles of axons was decreased. Single axons surrounded by a Schwann cell process were occasionally observed in anti-L1-treated cultures, but the bifurcation of Schwann cell processes was decreascd. Clcarly, the extension of Schwann cell processes was diminished in the treated cultures.

An important finding of the ultrastructural study was that anti-Ll treatment $(50 \mu \mathrm{g} / \mathrm{ml})$ markedly reduced the number of occurrences of axons and Schwann cell processes that were in a 1:1 relationship, compared with controls (Table 4). Schwann cell-axon units in this $1: 1$ relationship are readily distinguished in electron micrographs because they are physically separated from other cells and structures by space and extracellular matrix. The establishment of this monogamous relationship is a prerequisite for myelination and is the first morphological indication of impending myelination by a given Schwann cell. Apparently, the $\mathrm{L} 1$ antibody blocked a step required for the recognition and segregation of the myelin-competent axon by the Schwann cell, thus preventing a primary event of myelination.

\section{Anti-L1 does not block myelination by blocking basal lamina formation}

Because Schwann cell myelination is obligately linked to basal lamina formation (Eldridge et al., 1989), the effects of L1 antibody on myelination could result from an effect on basal lamina formation or on the interaction between the Schwann cell surface and basal lamina. We obtained 3 results that suggested that anti-L 1 blocks myelination by preventing an essential early axon-Schwann cell interaction and not by interfering with basal lamina formation. This evidence pertains to the formation of basal lamina, the deposition of laminin, and the inhibition of myelination in the presence of added laminin.

To compare basal lamina development, we examined (in electron micrographs) only those Schwann cells that were sectioned through the nuclcus and for which the entire cell perimeter was visible. This method of comparison was chosen to avoid counting more than 1 process from the same cell and to circumvent the problem of control cells extending more processes than antiL1-treated cells. Forty-six control and 43 anti-L1-treated (50 $\mu \mathrm{g} / \mathrm{ml}$ ) Schwann cells were examined (Table 3, Fig. 3). In control cultures, the basal lamina ranged from a loosely organized, discontinuous deposition of material on those Schwann cells that had extended processes within the fascicles of axons (Fig. $3 a$ ) to a better organized and usually continuous lamina on Schwann cells in 1:1 relationships with axon segments. The basal lamina
Table 2. Inhibition of myelination by Fab fragments of polyclonal anti-L1 antibody

\begin{tabular}{lcc} 
Condition & Myelin counts & $\begin{array}{c}\text { Inhi } \\
\text { tion }\end{array}$ \\
\hline Experiment 1 & & \\
A. Control & $177(175,160)^{a}$ & \\
$\quad$ Anti-L1 Fab $(250 \mu \mathrm{g} / \mathrm{ml})$ & $29(28,31)$ & 84 \\
B. Control & $123(106,140)$ & \\
$\quad$ Anti-liver $(250 \mu \mathrm{g} / \mathrm{ml})$ & $107(102,112)$ & 13 \\
Experiment 2 & $262(334,190)^{b}$ & \\
A. Control & $17(25,9)$ & 93 \\
B. Anti-L1 Fab, 4 d & $3(7,0)$ & 99 \\
C. Anti-Ll Fab, 6 d &
\end{tabular}

Myelin segments were counted on Sudan-black-slained whole-mounted cultures (see Materials and Methods). In experiment 2, some cultures were shifted for $2 \mathrm{~d}$ to $\mathrm{SA}+$ medium, then treated for $4 \mathrm{~d}$ with anti-L1 Fab (Group B). Other cultures were shifted directly into anti-L1-containing $\mathrm{S} \Lambda+$ medium for $6 \mathrm{~d}$ (Group C).

ayelin segments per $\mathrm{mm}^{2}$.

${ }^{3}$ Total number of segments counted.

was always most continuous and thickest on myelinating Schwann cells (i.e., those displaying 2 or more turns of the myelin spiral). A few Schwann cells displayed no deposition of basal lamina at all; these were usually Schwann cells in contact with axons but without processes extending within the axonal fascicles. Approximately the same percentage of Schwann cells had basal lamina deposition, and the general pattern of deposition appeared to be similar, in control and in anti-L1-treated cultures (Table 3). Clearly, many Schwann cells were able to deposit some basal lamina in the presence of the antibody (Fig. $3 b$ ). Furthermore, because basal lamina formation in neuronSchwann cell cultures requires contact between the axon and the Schwann cell (Clark and Bunge, 1989), the formation of basal lamina in the presence of anti-L1 implies that axonSchwann cell contact was not significantly altered by anti-L1.

To explore further the possibility of a subtle effect of anti-L1 on basal lamina formation, control and treated cultures were compared after immunostaining with a monoclonal antibody to laminin (Fig. $4 a-d$ ). As detected by this antibody, some, but not all, Schwann cells maintained in SA - medium weakly expressed laminin in a punctate pattern on their surfaces (Eldridge et al., 1987). Nearly all Schwann cells in cultures that were shifted to SA + medium displayed an increased deposition of laminin in a patchy to linear pattern on their surfaces $8 \mathrm{~d}$ after the shift (Fig. 4a,b); myelinating Schwann cells were brightly and continuously stained. Axons were not stained by anti-laminin, but because the axons were completely covered by longitudinally extending Schwann cell processes, the staining for laminin was continuous along the course of the axons. An increased laminin deposition was also observed on Schwann cells in cultures shifted to SA+/anti-Ll medium; however, the staining was not continuous along the axon (Fig. $4 c, d$ ). Our interpretation of this different staining pattern in the treated cultures is that the longitudinal extension of Schwann cell processes was decreased, and therefore the axons were not completely covered by laminin-positive processes as they were in controls. Possibly reflecting this shortening of the Schwann cell, the laminin staining in treated cultures often appeared brighter than that in controls. In both SA - and SA+/anti-L1 medium, the Schwann cells were often clustered together in groups, with uncovered 

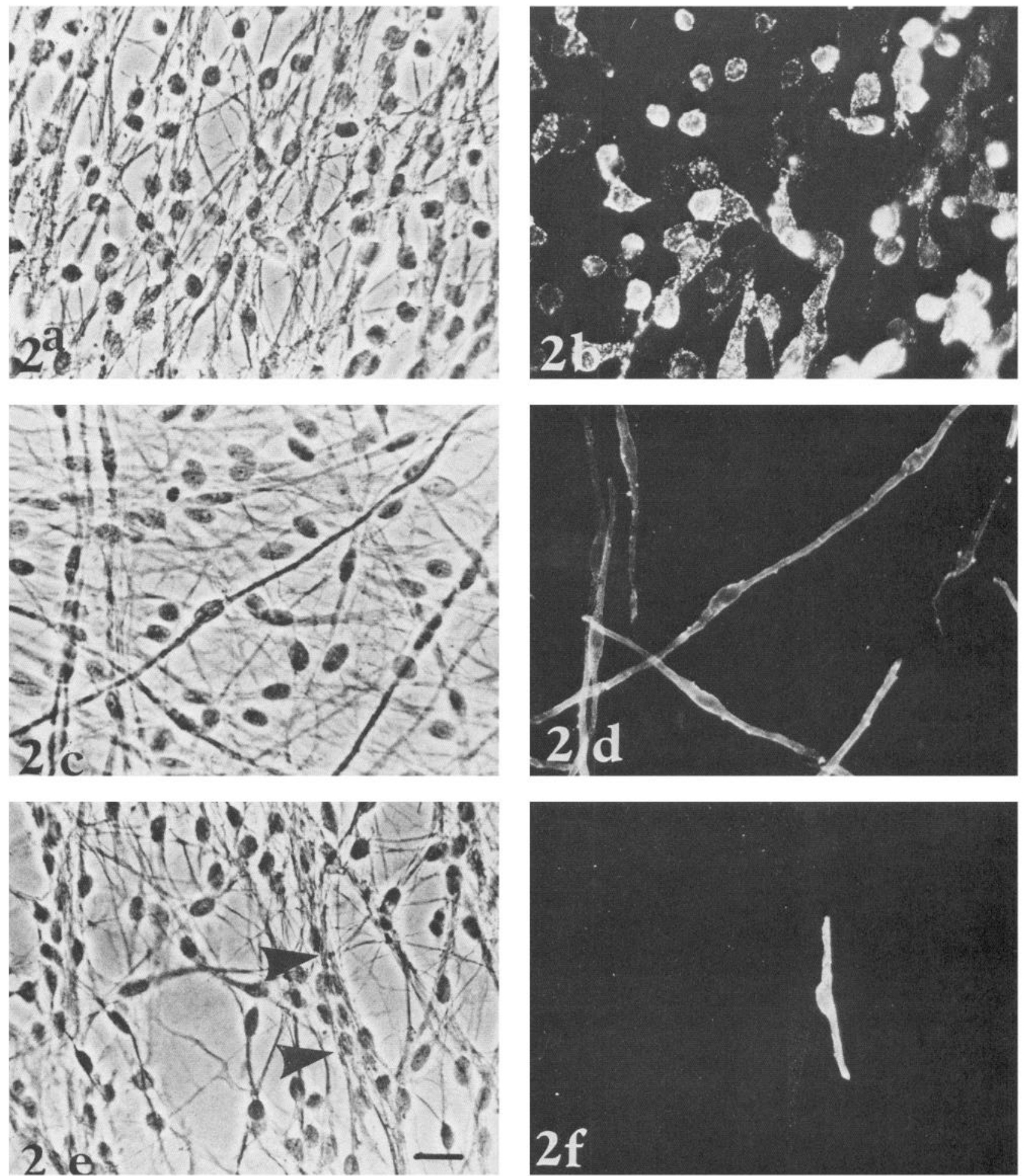

Figure 2. Effect of anti-L1 on Gal-C expression by Schwann cells. Phase-contrast $(a)$ and fluorescence $(b)$ images of Gal-C immunostaining in $\mathrm{SA}$ - medium at the point of shifting into SA + medium. Phase-contrast $(c)$ and fluorescence $(d)$ images of Gal-C immunostaining $10 \mathrm{~d}$ after shifting to SA+ medium. Note the change in the apparent length of Gal-C+ Schwann cells compared to those in SA- medium and the decrease in the number of Gal-C + cells overall in SA+ medium. Phase-contrast $(e)$ and fluorescence $(f)$ images of Gal-C immunostaining $10 \mathrm{~d}$ after shifting into $\mathrm{SA}+$ /anti-L1 Fab medium $(250 \mu \mathrm{g} / \mathrm{ml}$ anti-L1). Most Schwann cells were Gal-C-; when Gal-C+ Schwann cells were observed, they were, on average, shorter, and the presumptive myelin sheath exhibited only a weak contrast in the phase image (arrowheads). Scale bar, $10 \mu \mathrm{m}$.

axons between. Whereas the laminin staining on such Schwann cells in SA - medium was patchy or very faint, in SA+/antiL1 medium, it was bright and continuous. From these observations, it is clear that Schwann cells in SA+/anti-L1 medium released and bound laminin at levels roughly equivalent to those in control medium.

Although laminin was released by and deposited on the surfaces of the Schwann cells in anti-L1-treated cultures, the failure 

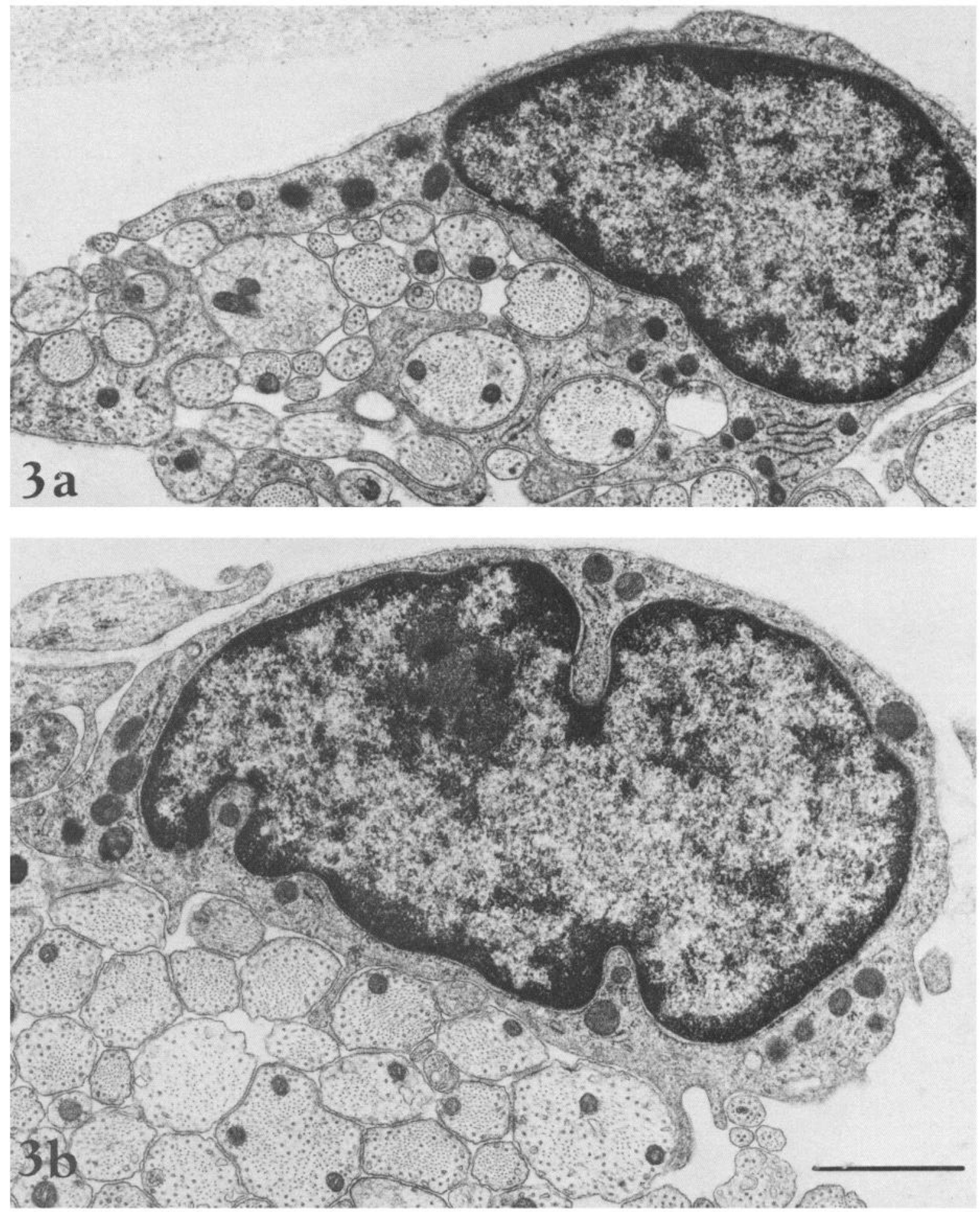

Figure 3. Electron micrographs of Schwann cells in control and anti-L1-treated cultures. $a$, This micrograph illustrates a control Schwann cell in a culture fixed $8 \mathrm{~d}$ after shifting from SA- to SA+ medium. Note the presence of a patchy basal lamina and the invasion of the axonal fascicle by Schwann cell processes. $b$, This micrograph illustrates a Schwann cell in a culture treated with anti-L1 antibody (50 $\mu \mathrm{g} / \mathrm{ml})$ in SA+ medium for $8 \mathrm{~d}$ prior to fixation. Note that some basal lamina material is present on the surface of the cell opposite the side contacted by axons. The Schwann cell appears to be in normal contact with the axonal surface, but there is little invasion of the fasicle by Schwann cell processes. Scale bar, $1 \mu \mathrm{m}$.

of the Schwann cells to elongate in anti-L1-treated cultures could reflect an altered interaction between the Schwann cell surface and its basal lamina not detectable by electron microscopy or by laminin staining. It has been shown that the addition of exogenous laminin causes a basal-lamina-like material to be deposited on Schwann cells even when they are maintained under conditions that do not permit basal lamina production by the cells themselves (e.g., ascorbate deprivation; Eldridge et al., 1989). It seemed likely, therefore, that any subtle effect of anti-L1 on basal lamina formation might be overridden by 
Table 3. Effect of anti-L1 antibody on basal lamina formation and axon engagement by Schwann cells

\begin{tabular}{llll} 
Condition & $\begin{array}{l}\text { Cells } \\
\text { examined }\end{array}$ & $\begin{array}{l}\text { Cells with } \\
\text { basal lamina } \\
(\%)\end{array}$ & $\begin{array}{l}\text { Cells } \\
\text { engaged } \\
\text { with axons } \\
(\%)\end{array}$ \\
\hline Control & 46 & 62 & 33 \\
Anti-L1 & 43 & 58 & 30
\end{tabular}

A cell was considered to have basal lamina if more than half of the surface of the cell not in direct apposition to axons was associated with basal lamina (i.e., basal lamina will not normally be deposited on the Schwann cell surface apposed to the axonal surface). A cell was considered to be engaged with axons if a process or processes extended by at least 1 axon diameter beyond the cell soma and into an axonal fasicle. The antibody concentration used in this experiment was $50 \mu \mathrm{g} / \mathrm{ml}$.

added laminin. For this reason, we repeated the myelinationblocking experiments, but in the absence and presence of $50 \mu \mathrm{g} /$ $\mathrm{ml}$ exogenous purified laminin derived from EHS sarcoma cells (see Materials and Methods). When laminin was added, we observed a bright, linear pattern of staining on the Schwann cell
Table 4. Effect of anti-L1 antibody on the segregation by Schwann cells of large axons into a 1:1 relationship

\begin{tabular}{llll} 
& $\begin{array}{l}\text { Total number } \\
\text { of Schwann cell } \\
\text { processes } \\
\text { counted }\end{array}$ & $\begin{array}{l}\text { Number of 1:1 } \\
\text { relationships } \\
\text { found }\end{array}$ & $\%$ \\
\hline Condition & 343 & 94 & 27 \\
Anti-L1 & 162 & 10 & 6
\end{tabular}

Electron micrographs taken at a final magnification of $21,500 \times$ were examined for profiles indicating that a 1:1 relationship had been established. Only processes cut in cross-section for which the complete perimeter was visible were counted. A 1:1 relationship was considered to be established if all the following criteria were met: (1) a mesaxon was present but compacted myelin lamellae were absent; (2) only a single axon was ensheathed, and (3) a basal lamina (even if patchy) surrounded the axon-Schwann cell unit. The antibody concentration used in this experiment was $50 \mu \mathrm{g} / \mathrm{ml}$.

surface in both control (SA+ medium with laminin added) and treated (SA+/anti-Ll medium with laminin added) cultures (Fig. $5 a-d$ ). Furthermore, in contrast to cultures treated with anti-L1 alone (SA+/anti-L1 medium), segments of uncovered
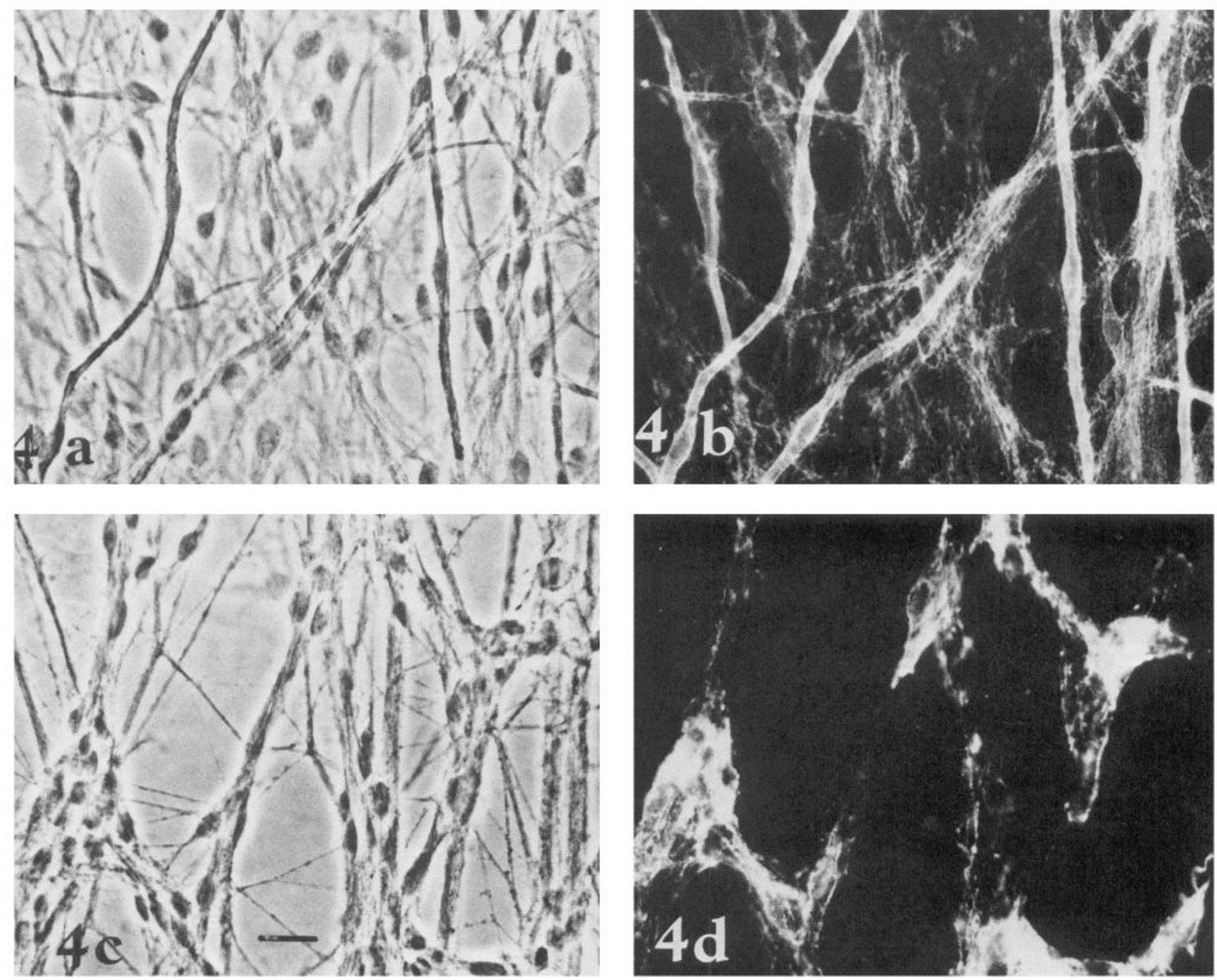

Figure 4. Laminin deposition on Schwann cells in control and anti-L1-treated cultures. Phase-contrast (a) and fluorescence (b) images of Schwann cells in a control culture stained $8 \mathrm{~d}$ after shifting from SA- to SA+ medium. Note the brighter staining for laminin on the myelin sheaths, consistent with an observed heavier deposition of basal lamina on myelinating Schwann cells than on nonmyelinating ones. Phase-contrast (c) and fluorescence $(d)$ images of cultures treated with $50 \mu \mathrm{g} / \mathrm{ml}$ anti- $\mathrm{Ll}$ antibody for $8 \mathrm{~d}$ and immunostained for laminin. Note the bright staining for laminin in clustered Schwann cells and lack of staining of bare axonal surfaces. Scale bar, $10 \mu \mathrm{m}$. 

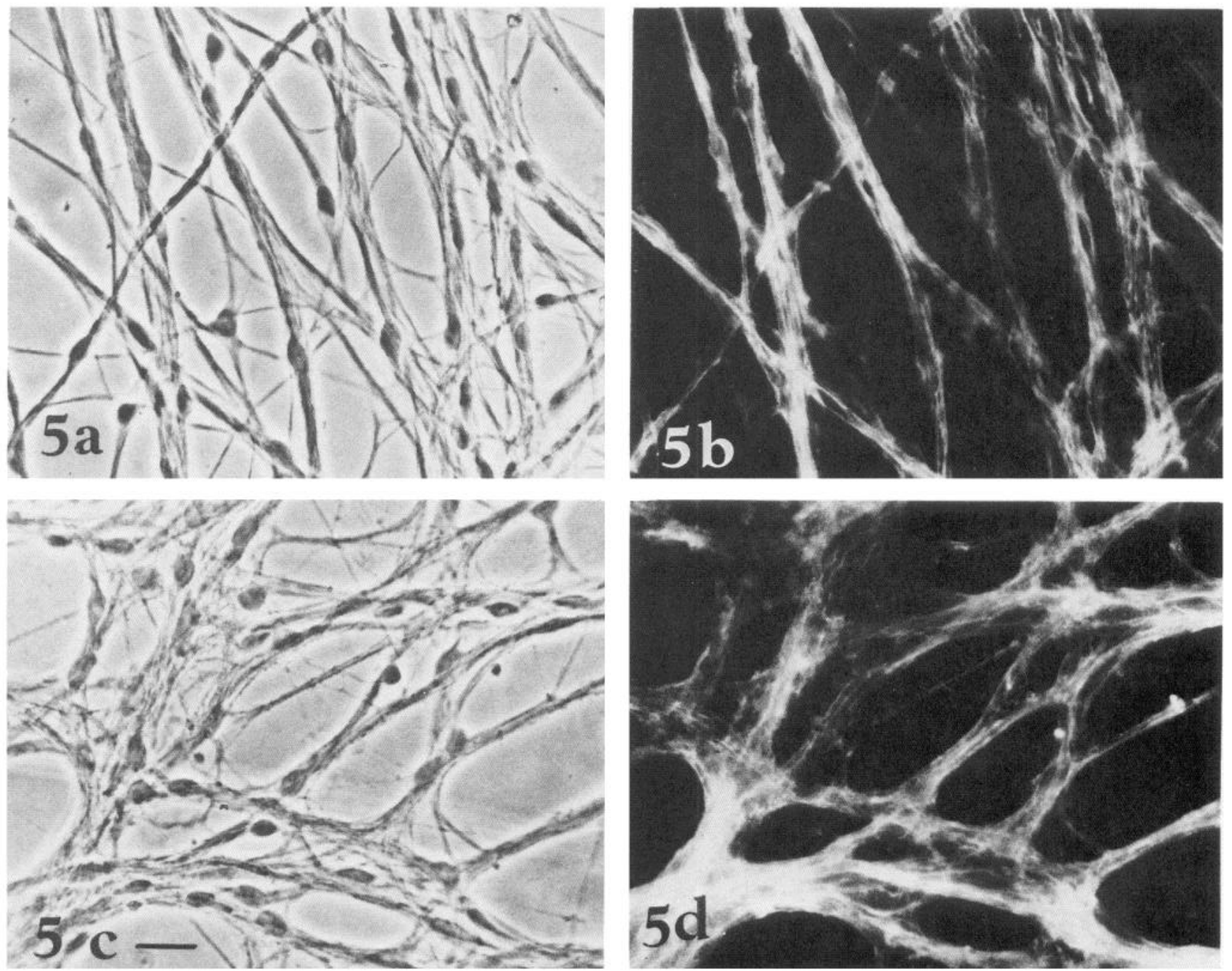

Figure 5. Laminin deposition on Schwann cells in control and anti-L1-treated cultures in presence of exogenous laminin. Phase-contrast (a) and fluorescence $(b)$ images of Schwann cells in a control culture maintained for $8 \mathrm{~d}$ in SA+ medium containing $50 \mu \mathrm{g} / \mathrm{ml}$ added purified laminin. The cultures were then immunostained for laminin. Note bright linear laminin staining on nonmyelinating Schwann cells. Phase-contrast (c) and fluorescence $(d)$ images of Schwann cells in an anti-L1-treated culture maintained for $8 \mathrm{~d}$ in SA+ medium containing $20 \mu \mathrm{g} / \mathrm{ml}$ anti-L1 antibody and $50 \mu \mathrm{g} / \mathrm{ml}$ laminin. Note the bright linear laminin staining on nonmyelinating Schwann cells and absence of stretches of bare axonal surface (cf. Fig. $4 d$ ). Scale bar, $10 \mu \mathrm{m}$.

(laminin-negative) axons were not observed in cultures treated with anti-L1 and laminin, and the Schwann cells did not form clusters (cf. Figs. $4 d, 5 d$ ). These results suggest that the longitudinal extension of Schwann cell processes along axons (which was inhibited by anti-L1 in the absence of added laminin) was not inhibited by anti-L1 when excess laminin was present. Furthermore, in both control and anti-L1-treated cultures to which laminin was added, we observed by electron microscopy that the Schwann cell surfaces were draped with an abundant basallamina-like material. Despite the apparent equivalence in Schwann cell morphology and basal lamina deposition between control and anti-L1-treated cultures when exogenous laminin was added, myelination continued to be dramatically inhibited by the anti-Ll antibody (Table 5 ).

To summarize this evidence, a gross disruption of basal lamina formation did not occur as a result of anti-L1 treatment. Approximately equal percentages of Schwann cells in control and treated cultures possessed some basal lamina on their surfaces and in roughly equal amounts, and substantial laminin deposition could be observed on most Schwann cells in antiL1-treated cultures. The addition of exogenous laminin increased the deposition of laminin and basal-lamina-like material in both control and treated cultures and apparently supported the elongation and extension of Schwann processes in the antiL1 treated cultures, but did not prevent the inhibition of myelination by anti-L1. These observations argue that the effect of anti-L1 on myelination is the result of disruption of an axonSchwann cell interaction essential for myelination, and not the result of an effect on basal lamina formation.

\section{Discussion}

The major new result we present here is that antibodies to the $\mathrm{L} 1$ adhesion molecule consistently and dramatically blocked the formation of myelin sheaths by Schwann cells. Furthermore, anti-L1 antibody blocked the expression of the myelin lipid Gal$\mathrm{C}$, which, along with MAG expression, is one of the earliest known events in myelination (Norton, 1977; Tennekoon et al., 
Table 5 . Inhibition of myelination by anti-L1 antibody in the absence and presence of exogenous laminin

\begin{tabular}{|c|c|c|}
\hline Condition & Myelin quantity & $\begin{array}{l}\text { Percent of } \\
\text { control }\end{array}$ \\
\hline Control & $991 \quad(1127,855)$ & 100 \\
\hline Anti-Ll & $9.5(6,13)$ & 1 \\
\hline Control + laminin & $1367 \quad(1176,1557)$ & 100 \\
\hline Anti-Ll + laminin & $86 \quad(121,51)$ & 6 \\
\hline
\end{tabular}

Myelination was quantitated on whole-mounts of Sudan-black-stained cultures (see Materials and Methods). Intact anti-Ll antibody was added at $20 \mu \mathrm{g} / \mathrm{ml}$. Because in this experiment control cultures were too heavily myelinated to count for individual segments, myelination was quantitated using an eyepiece grid of 100 squares. The number of squares in this grid crossed completely by a portion of a myelin segment or segments was determined for each field. The numbers in the table are the total numbers of squares containing myelin in 25 fields selected in each culture by stage coordinates. The determination was made for duplicate cultures in each group, and the average is shown, with individual values in parentheses.

1980; Trapp et al., 1984; Owens and Bunge, 1989). The antibody also inhibited the segregation by Schwann cell processes of large axons into the $1: 1$ relationship that precedes myelination. These results suggest that the $L 1$ antibody prevents an interaction that either distinctly precedes or is one of the earliest specific events of the process of myelination.

Under the conditions of our experiments, we did not observe significant effects of anti-Ll on either axon-Schwann cell adhesion or on basal lamina formation by the Schwann cells. These results are different from those reported earlier (Seilheimer and Schachner, 1988; Seilheimer et al., 1989b). We bclicve thesc differences are best explained by differences in the stage of development of the axon-Schwann cell interaction at which the anti-L1 was introduced. In the earlier work, anti-L1 was introduced before axon-Schwann cell adhesion was established. In the experiments reported here, anti-Ll was introduced after adhesion was well established. Our results therefore suggest that Ll may be only 1 of several molecules mediating neuronSchwann cell adhesion. The lack of effect of anti-L1 on basal lamina formation is further evidence that axon-Schwann cell contact, which is a prerequisite for basal lamina formation by the Schwann cell (Clark and Bunge, 1989), was unaffected.

From these considerations, it appears unlikely that the strong inhibition of myelination by anti- $\mathrm{Ll}$ was due to effects on the adhesion of the Schwann cell to the axon or on basal lamina formation. We suggest that anti-L1 blocks myelination directly by interfering with a critical L1-mediated interaction between the axonal surface and the apposing Schwann cell membrane. Because of the much greater abundance of L1 on the axonal than on the Schwann cell membrane (present observations) and because $\mathrm{L} 1$ rapidly disappears from the myelinating Schwann cell surface (Martini et al., 1986; Martini and Schachner, 1988; present observations), we further purpose that it is specifically axonal $\mathrm{L} 1$ that is most important in this interaction. This axonal L1 may mediate or be a part of a multimolecular complex underlying the mobilization or reorganization of the Schwann cell cytoskeleton that supports the extension of Schwann cell processes and/or engulfment of axons. The formation of this complex would be initiated by the binding of axonal L1 to a receptor on the Schwann cell surface. This receptor could be linked to cytoskeletal elements either directly or via other transmembrane proteins (for precedents, see Chen et al., 1985; Pollerberg et al., 1987; Yannariello-Brown et al., 1988; Akiyama et al., 1989). The blocking of $\mathrm{Ll}$ would disrupt the formation of this transcellular complex and prevent succeeding events that depend on it.

The lack of effect of anti-L1 on axon-driven Schwann cell proliferation reported earlier (Seilheimer et al., 1989b; N. Ratner, unpublished observations) or on basal lamina formation demonstrates that not all differentiative events are dependent on L1. However, the expression of Gal-C (present observations) and MAG (Seilheimer et al., 1989b) were blocked by the antibody. This suggests an involvement of $\mathrm{Ll}$ in inductive events specific for myelination, that is, in the induction of $\mathrm{Gal}-\mathrm{C}$ and MAG synthesis. Recently, it has been shown that antibodies in either L1 or NCAM could reduce the level of inositol phosphates in $\mathrm{PC} 12$ cells (Schuch et al., 1989), suggesting that these celladhesion molecules could directly influence second-messenger systems within the cell and thus be involved in the signaling mechanism by which axons may help to regulate the initiation of myelinating activities in the Schwann cell. Therefore, an alternative explanation for how anti-L1 blocks myelination is that it might specifically block the induction of synthesis of Schwann cell molecules critical for the growth of the myelin sheath.

The relationship between axons and Schwann cells in higher vertebrates is unique in the expanse of surface membranes that are juxtaposed in close contact and in the large number of ways that the function of each cell depends on the other. Our present results support earlier indications that $\mathrm{L} 1$ is a major element in the complex interaction by which this relationship develops. We anticipate that future experiments will further resolve the role of L1 and lead to an improved understanding of these important developmental cvents.

\section{References}

Akiyama S, Yamada S, Chen W-T, Yamada KM (1989) Analysis of fibronectin receptor function with monoclonal antibodies: roles in cell adhesion, migration, matrix assembly and cytoskeletal organization. J Cell Biol 109:863-875.

Bixby JL, Lilien J, Reichardt L (1988) Identification of the major proteins that promote neuronal process outgrowth on Schwann cells in vitro. J Cell Biol 107:353-361.

Bunge MB, Bunge RP, Carey DJ, Cornbrooks CJ, Eldridge CF, Williams AK, Wood PM (1983) Axonal and nonaxonal influences on Schwann cell development. In: Developing and regenerating vertebrate nervous systems (Coates PW, Markwald RR, Kenny AD, eds), pp 71-105. New York: Liss.

Bunge RP, Bunge M, Bates M (1989) Movements of the Schwann cell nucleus implicate progression of the inner (axon-related) Schwann cell process during myelination. J Cell Biol 109:273-284.

Chen W-T, Hasegawa L, Hasegawa T, Weinstreb C, Yamada K (1985) Development of cell surface linkage complexes in cultured fibroblasts. J Cell Biol 100:1103-1114.

Clark B, Bunge MB (1989) Culturcd Schwann cells assemble normalappearing basal lamina only when they ensheath axons. Dev Biol 133: 393-404.

Eldridge CF, Bunge MB, Bunge RP, Wood PM (1987) Differentiation of axon-related Schwann cells in vitro. I. Ascorbic acid regulates basal lamina assembly and myelin formation. J Cell Biol 105:1023-1034.

Eldridge $\mathrm{CF}$, Bunge $\mathrm{MB}$, Bunge RP (1989) Differentiation of axonrelated Schwann cells in vitro: II. Control of myelin formation by basal lamina. J Neurosci 9:625-638.

Engvall E, Davis G, Dickerson K, Ruoslahti E (1986) Mapping of domains in human laminin using monoclonal antibodies: localization of the neurite-promoting site. J Cell Biol 103:2457-2465.

Faissner A, Kruse J, Nieke J, Schachner M (1984) Expression of neural cell adhesion molecule $\mathbf{L l}$ during development in neurological mutants and in the peripheral nervous system. Dev Brain Res 15:69-82.

Kleitman N, Simon DK, Schachner M, Bunge RP (1988) Growth of embryonic retinal neurites elicited by contact with Schwann cell surfaces is blocked by antibodies to L1. Exp Neurol 102:298-308.

Lindner J, Rathjen FG, Schachner M (1983) L1-mono- and polyclonal 
antibodies modify cell migration in early postnatal cerebellum. Nature 305:427-430.

Martini R, Schachner M (1986) Immunoelectron microscopic localization of neural cell adhesion molecules (L.1, N-CAM, and MAG) and their shared carbohydrate epitope and myelin basic protein in developing sciatic nerve. J Cell Biol 103:2439-2448.

Martini R, Schachner M (1988) Immunoclectron-microscopic localization of neural cell adhesion molecules (L1, N-CAM, and myelin associated glycoprotein) in regenerating adult sciatic nerve. J Cell Biol 106:1735-1746.

Mithen F, Wood P, Agrawal H, Bunge RP (1983) Immunohistochemical study of myelin sheaths formed by oligodendrocytes interacting with dissociated dorsal root ganglion neurons in culture. Brain Res 262:63-69.

Norton W (1977) Isolation and characterization of myelin. In: Myelin (Morrell P, ed), pp 161-199. New York: Plenum.

Owens G, Bunge RP (1989) Evidence for an early role for myelinassociated glycoprotein in the process of myelination. Glia 2:119128.

Pollerberg GE, Burridge K, Krebs K, Goodman SR, Schachner M (1987) The 180-KD component of the neural cell adhesion molcculc N-CAM is involved in cell-cell contacts and cytoskeletal membrane interactions. Cell Tissue Res 250:227-236.

Porter RP (1959) The hydrolysis of rabbit gamma globulin and antibodies with crystalline papain. Biochem J 73:119-131.

Ranscht B, Clapshaw PA, Price J, Noble M, Seifert W (1982) Development of oligodendrocytes and Schwann cells studied with a monoclonal antibody against galactocerebroside. Proc Natl Acad Sci USA 79:2709-2713.

Ranscht B, Wood PM, Bunge RP (1987) Inhibition of in vitro peripheral myelin formation by monoclonal anti-galactocerebroside. J Neurosci 7:2936-2947.
Rathjen FG, Schachner M (1984) Immunocytochemical and biochemical characterization of a new neuronal cell surface component (L1 antigen) which is involved in cell adhesion. EMBO J 3:1-10.

Schuch U, Lohse MJ, Schachner M (1989) Neural cell adhesion molecules influence second messenger systems. Neuron 3:13-20.

Seilheimer B, Schachner M (1988) Studies of adhesion molecules mediating interactions betwecn cclls of pcriphcral nervous system indicate a major role for $\mathrm{Ll}$ in mediating sensory neuron growth on Schwann cells in culture. J Cell Biol 107:341-351.

Seilheimer B, Persohn E, Schachner M (1989a) Neural cell adhesion molecule expression is regulated by Schwann cell-neuron interactions in culture. J Cell Biol 108:1909-1915.

Seilheimer B, Persohn E, Schachner M (1989b) Antibodies to the L1 adhesion molecule inhibit Schwann cell ensheathment of neurons in vitro. J Cell Biol 109:3095-3104.

Tennekoon GI, Kishimoto Y, Singh I, Nonaka G, Bourre JM (1980) The differentiation of oligodendrocytes in rat optic nerve. Dev Biol 79:149-158.

Thiery JP, Brackenberry R, Rutishauser U, Edelman GM (1977) Adhesion among neural cells of the chick embryo. II. Purification and characterization of a cell adhesion molecule from neural retina. J Biol Chem 252:6841-6845.

Trapp B, Quarles R, Suzuki K (1984) Immunocytochemical studies of quaking mice support a role for myelin-associated glycoprotein in forming and maintaining the periaxonal space and periaxonal collar of myelinating Schwann cells. J Cell Biol 99:594-606.

Yannariello-Brown J, Wewer U, Liotta L, Madri J (1988) Distribution of a 69-kD laminin-binding protein in aortic and microvascular endothelial cells: modulation during cell attachment, spreading, and migration. J Cell Biol 106:1773-1786. 